\title{
Angelus Novus Looks to the Future. On the Anti-Humanism which Overcomes Nothingness
}

Olga Cielemęcka 
Olga Cielemęcka

\section{Angelus Novus Looks to the Future On the Anti-Humanism which Overcomes Nothingness}

DOI: 10.18318/td.2015.en.1.6

$\mathbf{T}$ he question of the human being's relation to the nonhuman might be the most important of all those that contemporary philosophy has to answer. The non-human is a broad category: machines and new technologies, animals along with the whole natural world - all have their place within it. In the era of late capitalism, ruled by technology and information, a change is occurring that no longer allows us to perceive man (sic) as the master of nature or technology. Rather s/he is surrounded on all sides by that which is non-human; what s/he herself or himself produces, and by which s/he herself or himself is produced.

Until recently the non-human constituted a necessary point of reference for the emergence, in opposition to it, of that which is genuinely human. Whether it was God, a superhuman entity, or Nature, the part they played was the same: they provided a differentiation point for the sphere of the human, which diverges from both the natural and supernatural. Since the times of ancient Greece until modernity efforts were undertaken to determine some kind of trait, ability or quality that would enable the discovery of a human differentia specifica. This trait was supposed to delimit a borderline beyond which a privileged space of human existence begins, which is

\author{
Olga Cielemęcka - \\ a postdoc at the Unit \\ of Gender Studies, \\ Department of \\ Thematic Studies, \\ Linköping University. \\ She holds a PhD in \\ philosophy from \\ Warsaw University \\ in Poland. She \\ was a research \\ assistant at the \\ Wirth Institute at \\ University of Alberta \\ in Canada, and a \\ visiting researcher \\ at ICON, Utrecht \\ University. She brings \\ together research \\ within the domains \\ of contemporary \\ philosophy, \\ feminist theory, and \\ posthumanism, in \\ an effort to re-think \\ the concepts of the \\ subject, community, \\ and collaboration \\ in the times of \\ advanced capitalism \\ and environmental \\ change.
}


different from the life of animals and inanimate entities. Different periods in the history of ideas and science determined this strictly human feature to be, among many others, the possession of either the mind or the soul, being the creation of God made in his image and likeness, the ability to produce language, create tools or accumulate knowledge. Giorgio Agamben sees in a fragment from Aristotle's On the Soul the foundation for the kind of thinking about man that must necessarily establish some trait that is strictly human. Aristotle enumerates three kinds of souls, of which only one is essentially human and is not possessed by any other creature. It is all about "that human beings be human and not inhumane"1, and for this to happen, they must detach and differentiate from that which is non-human within themselves.

The shift we are currently witnessing is an outcome of the realization that the difference between the human and non-human is not solid enough to shield that which is human from the non-human. The non-human destabilizes previous concepts of subjectivity, forces questions addressing the human being's place in the world. But what exactly do we have in mind when we talk about the non-human?

First of all, the non-human encompasses the broad category of machines, not only the technological ones like robots, cyborgs, networks of virtual communication and flow of capital, but most of all the machines of power. The non-human is also an ethical category, inclusive of those who are marginalized, those who are dehumanized or those deprived of human rights. Finally, the non-human refers to the animal. The issue of animal rights and human obligations towards them derives from a much more fundamental realization: that the difference between the human and the animal is possibly an arbitrary one, it undergoes shifts and changes up to the point of dissolution.

These three fields, to which I narrow down the concept of the non-human, are accompanied by three corresponding types of anxiety. The first is the anxiety of dehumanization of man by machinery. Not only by emerging technologies, for example cellular phones of which Giorgio Agamben was so critical, but by the power itself, the social structure, that which transcends humanity and produces it and at the same time is imagined as a kind of machine. Secondly, the social exclusion, ethnic cleansing, colonization, slavery and concentration camps - the whole baggage of cruelty in the administering of which the twentieth century was so adroit, leads to the conclusion that simply acknowledging that a being is human does not protect it from violence. Moreover, it arouses a kind of suspicion that the term "human" is an

1 Martin Heidegger, Letter on 'Humanism', in Pathmarks, ed. William McNeill (Cambridge: Cambridge University Press 1998), 244. 
instrument of control and exclusion of those who have been denied their humanity. Classical philosophical and ethical concepts: man, humanity, human dignity, the sanctity of human life, progress, all become useless and discredited. What exposes their disgraceful inadequacy is primarily the experience of Shoah that is fundamental for the entire twentieth century philosophy. Thirdly, facing that which is animal reveals the fear of mixing the human with the animal (or machine), of blurring the borderlines separating them from one another.

In reaction to the crisis of faith in the human, the "death of man" has been proclaimed. At first the concentrated attack of the non-human, from which there is no escape, causes philosophy to wave a white flag by declaring the end of history, the destruction of metaphysics, the death of subjectivity and finally the end of man. Postmodern thinkers delight in this beautiful catastrophe by shattering notion after notion that philosophy relied upon until now. Nevertheless one cannot equate anti-humanism with decadence, or nihilism. Pessimism arising from the realization that nothing shields the human from the influx of the non-human, that the notion 'human' in the present form cannot be saved, is opposed by another mode of thinking, one which regards the death of man as a chance for liberation, and the non-human, instead of being perceived as a threat and catastrophe, is recognized as a creative, productive and sometimes even potentially liberating area. This affirmative and militant anti-humanism not only opposes humanism, but can also keep up its tradition. As Antonio Negri and Michael Hardt write:

Once we recognize our posthuman bodies and minds, once we see ourselves for the simians and cyborgs we are, we then need to explore the vis viva, the creative powers that animate us as they do all of nature and actualize our potentialities. This is humanism after the death of Man: what Foucault calls "le travail de soi sur soi," the continuous constituent project to create and re-create ourselves and our world ${ }^{2}$.

It is precisely this shift in attitude that will be the object of my consideration. I will delineate three areas wherein it takes place. The starting point in each case will be the intertwinement of the human with the non-human: life with power, the organic with the mechanical and the human with the animal. The sheer impossibility of their clear differentiation inspires the idea of a new kind of figuration of subjectivity.

The weakening of the subject, taking place in the twentieth century in the works of thinkers most prominent of whom are perhaps Michel Foucault

2 Michael Hardt and Antonio Negri, Empire (Cambridge: Harvard University Press, 2001$), 92$. 
and Jacques Lacan, leads to the placement of the mechanisms of power or language, that are responsible for the production of human beings, in the spotlight of theoretical deliberation. The subject becomes subdued to their rule, reduced to a mere derivative of non-human mechanisms: a product of power or an effect of language. The notion I will examine within this context is biopolitics. Imagined in the form of machinery that produces subjectivity in an oppressive manner, it is an expression of the subsumption of the subject under that which is non-human; biopolitics is a system, a network, a machine within which the subject is submerged. Contrary to this viewpoint I will attempt to present biopolitics in its creative aspect that allows it to become a synonym for creative resistance within the apparatuses of power.

The death of the subject might have been merely a consequence of the struggle against the enlightenment "myth of liberation through rationality" that was in progress since the Second World War. The critique of instrumental and technical reason, shaped by Heidegger, Adorno and Horkheimer, and the following despondency in the face of mass society's growing idiocy, a society controlled by the media and the advertising industry, leads to the conviction that technological progress is the sole culprit responsible for every misery, from the Holocaust to the complete disregard for Being. Media, machinery and technology bring about inhumanity, oppression and stultification. In opposition to the dominant anti-technological attitude there emerged a theoretical reflection on contemporary reality, positing that the ever-present creations of technology and human beings must not necessarily engage in conflict, but can cohabit and reshape their world. In consequence, a cyborg or hybrid - creations blending the human with the non-human - have become a model for human subjectivity.

Finally, the issue of the relations of that which is human to the animal. The monolithic, auto-assertive and self-conscious subject, the master of nature and creator of technology, turns out to be an inadequate model of subjectivity for the purpose of describing the place and role of the human being within the universe. This crisis opens a possibility of perceiving the human being not as residing within a privileged space beyond or above the animal kingdom, but within its borders. To this peculiar transfer of the human being into the sphere of the non-human, the decentralization that "places man back within the animal, within nature, and within a space and time that man does not regulate, understand or control?"3, I will dedicate the final part of this paper.

3 Elizabeth Grosz, Becoming Undone. Darwinian Reflections on Life, Politics, and Art (Durham: Duke University Press, 2011) 25. 


\section{Biopolitics and Its Discontents}

'Biopolitics' is an important notion that helps describe the invasion of the non-human that is a cause of shift in the perception of the human subject. Biopolitics equals a mix of life and power, one where technology of power not only takes human life into its grasp but also remodels it and finally becomes responsible for its production. In the form Michel Foucault gave to the term in the seventies biopolitics denotes an essential reshaping of politics at the end of the eighteenth century, when biological life was introduced into the mechanisms of state rule. From then on governments took upon themselves the responsibility for the life of both the individuals and the human multitude. This results in a state of affairs where, on the one hand, biopolitics disciplines the individual body and through norms, which are the basic form of exercising biopolitics, "had assigned itself the task of administering life" . On the other hand, the population as a whole comes to the forefront of political attention. It will be governed by means of birth and mortality control, the control of health, hygiene, sexuality, nutrition and housing conditions, all of this is accompanied by advancements in specific forms of knowledge and scientific disciplines, such as statistics, demographics or epidemiology: "biopolitics will derive its knowledge from, and define its power's field of intervention in terms of, the birth rate, the mortality rate, various biological disabilities, and the effects of the environment" 5 . Namely, the main goal of this new type of power will be the issue of "regulating populations"6.

Biopolitics is, as Foucault writes, "what brought life and its mechanisms into the realm of explicit calculations and made knowledge-power an agent of transformation of human life"7. Power envisioned this way seems radically non-external and this means there is no escaping it. A human being tightly entangled by the web of power is situated within its very center and through normalizing operations, which s/he is subjected to, s/he eventually becomes indistinguishable from it. Power transcends life, absorbing the minds and bodies of its subjects. Biopower rules by proxy of institutions and mechanisms, but embeds itself deep within the very core of subjectivity and corporeality. "The control of society over individuals is not conducted only through consciousness or ideology, but also in the body and with the body.

\footnotetext{
4 Michel Foucault, The History of Sexuality. Volume 1: An Introduction (New York: Random House, 1990), 137.

5 Michel Foucault, "Society Must be Defended". Lectures at the College de France, 1975-76, ed. Mauro Bertani et al. (New York: Picador, 2003), 245.

6 Foucault, The History of Sexuality, 146.

7 lbid., 143 .
} 
For capitalist society biopolitics is what is most important, the biological, the somatic, the corporeal"8. This makes biopolitics not only a politics of administering bodies, but a procedure of producing them, trimmed and fitted according to its needs.

The notion of biopolitics became crucial in late twentieth-century thought, as it framed anxieties stemming from the ongoing political, economic and societal changes of the time. The fall of the Soviet Union paved the way for an uninterrupted procession of capitalism, a system for which there seems to be no alternative. The developments in the field of medicine, overshadowed by racist and eugenic experiments of the Nazis, gave rise to fears of a new advanced form of eugenics. Novel and perpetually perfected technologies, that are supposed to guarantee safety, have become a source of growing anxiety about our lives and health. The dense, suffocating web of biopolitical power, engrossing and controlling every aspect of human life, brings about the premonition that there no longer are any areas of freedom, a blank space free of the omnipotence that has cunningly, nearly unperceived, claimed the whole realm of human existence. Man ceased being a slave only to become a debtor - as Deleuze proclaimed.

If Foucault has assigned the birth of biopolitics a place in time, associating it with the dominance of capitalism and modern racism, then the development of this notion, in the form given to it by the Italian thinker Giorgio Agamben, came with the realization that every power is already biopolitical. Rule over life constitutes the irremovable core of power, and the modern state that has the biological body for its central object "therefore does nothing other than bring to light the secret tie uniting power and bare life, thereby reaffirming the bond $[. .$.$] between modern power and the most immemorial of the$ arcana imperii".

According to Aristotle, man is zoon politikon, a free citizen, who beside the biological dimension of life is granted the specifically human - political mode of existence. The political dimension of life is synonymous with human freedom, equality and dignity. However, biopolitics acknowledges only the animalistic, biological side of human life that forms the object of power, becomes politicized. If "for millennia, man remained what he was for Aristotle: a living animal with the additional capacity for a political existence; modern man is an animal whose politics places his existence as a living being in question"10.

8 Michael Foucault, La naissance de la médecine sociale, after Hardt and Negri, Empire, 27.

9 Giorgio Agamben, Homo Sacer. Sovereign Power and Bare Life (Stanford: Stanford University Press, 1998), 6. 
In ancient Greece the division of forms of life into bios and zoe, where zoe referred to the form of life common to all living creatures, and bios referenced a particular, defined form of life that can be properly attributed only to a certain individual or group; meant that bios was specific only to the life of human beings and possessed a certain quality. According to Giorgio Agamben, this ancient distinction between bios and zoe is the cornerstone of biopolitics. The Italian thinker is interested in the splitting of the meaning of the word 'life' in two: in its aftermath not every man's life is a truly human life, as not everyone is granted a bios politikos. Precisely this division into diverging, incompatible forms of life is the source of the emergence of the biopolitical body, of the bare or sacred life, as Agamben calls it. The philosopher claims: "It is as if every valorization and every «politicization» of life [...] necessarily implies a new decision concerning the threshold beyond which life ceases to be politically relevant, becomes only «sacred life», and can as such be eliminated without punishment"11. Inner tension and inconsistency thus enter the definition of "life" and "human". Agamben identifies the form of life that is common to all people - the bare life, as a field of political play, and a space of enslavement. In itself it is not subject to any kind of protection, it is not granted any rights, dignity or sanctity. Chronicling the delineation of borders between the bare life and the political existence might be the most ambitious task Agamben sets out to accomplish through his works, where he attempts to reach deep into the "uncertain and nameless terrains, these difficult zones of indistinction"12, where the human and non-human, politics and life, bios and zoe, physis and nomos mix together. Eventually the line separating them "moved inside every human life and every citizen. Bare life is no longer confined to a particular place or a definite category. It now dwells in the biological body of every living being"13.

Each life turns out to be subjected to power that, being biopolitical, reveals simultaneously its thanatopolitical dimension. The concept of biopolitics exposes the subject's lack of autonomy, its subordination to the mechanism that rules life and death, and which includes or excludes her, him or them from the set consisting of what is human. It constitutes an uncertain division between human and non-human that is the source of the violence of exclusion. According to Foucault, biopolitics is about producing and controlling docile bodies, for Agamben it is about being excluded from or being included in humanity. Recognizing the biopolitical character of power seems to enclose that

11 Agamben, Homo Sacer, 139.

12 lbid., 187.

13 Ibid., 140. 
which is human in a vicious circle of exclusion, enslavement, subordination, death. Contrary to this pessimistic reflection upon biopolitics the theories of both Foucault and Agamben have within themselves seeds of resistance to the biorule exerted over human life. In both cases these emancipatory themes reveal points of friction within the dense structure of biopower.

In The Will to Knowledge Foucault leaves a clue to a possible strategy of resistance to power: "Where there is power, there is resistance [...] so too the swarm of points of resistance traverses social stratifications and individual unities"14. In the network structure of power there are points of possible intervention, cracks inherently present in the system. Although there is no area beyond power, the subject is capable of a momentary revolt against it. At the end of the eighties an American theorist - Judith Butler - further developed the Foucaultian theories with a focus precisely on these points of resistance within biopower. Butler proposed a strategy of political emancipation based on the practice of parodic repetition of the repressive norms ruling human life, through which the whole system of power becomes disrupted ${ }^{\mathbf{1 5}}$. Likewise, Agamben in his formulation of biopower sees a certain weak possibility of resistance. In the division between bare life and political existence he introduces an irreducible point, which is governed by a different kind of logic than biopolitics, and for this reason "turns into an existence over which power no longer seems to have any hold"16, becoming a point of resistance, which biopolitics cannot overpower. Bare life, on the one hand, expresses the tragic impossibility of escaping power, but on the other hand, although it remains absolutely passive, it brings hope for its deactivation.

These weak forms of resistance against biopower, which are hinted at by Foucault and Agamben, are derivative of the structure of power itself, they are its effect. At the same time they are a kind of a crack or a "glitch" in the system. Antonio Negri and Michael Hardt, the authors of Empire, conceptualize the possibility of emancipation differently. They wish for the kind of resistance that is not situated in the margins, within the cracks of the system, but one that looks beyond the "horizon of destruction and death that still smolders behind us"17.

\footnotetext{
14 Foucault, The History of Sexuality, 93.

15 Judith Butler, Gender Trouble. Feminism and the Subversion of Identity (New York: Routledge, 1999).

16 Agamben, Homo Sacer, 153.

17 Antonio Negri, "The Italian Difference" in The Italian Difference. Between Nihilism and Biopolitics, ed. Lorenzo Chiesa and Alberto Toscano (Melbourne: re.press, 2009$), 21$.
} 
They differentiate between biopower and biopolitics - both terms were not precisely distinguished by either Foucault or Agamben - and offer a completely new, affirmative, articulation of the notion of biopolitics. "Biopower stands above society, transcendent, as a sovereign authority and imposes its order. Biopolitical production, in contrast, is immanent to society and creates social relationships and forms through collaborative forms of labor"18. Biopolitics according to Negri and Hardt unexpectedly becomes a useful tool in the development of a political ontology of a revolutionary subject. A way of overcoming the inertia of the suffering, submissive homo sacer and of construing a new subjective figuration expressing a certain kind of a power of being.

Biopolitics becomes a creative and productive field wherein the angel of history, Angelus Novus, that looks to the past and "sees one single catastrophe which keeps piling wreckage upon wreckage and hurls it in front of his feet"19 can now trustingly turn his gaze towards the future ${ }^{20}$.

This kind of looking forward is impossible, according to the authors of Empire, on the grounds of Foucaultian biopolitics, where it remains an inhuman machine of ruling that claims its right over human life, gorging on subjectivities ${ }^{\mathbf{2 1}}$. Negri and Hardt accuse Foucault of proposing an excessively static view of biopolitics, one that does not take into account the shift from its modern to its postmodern form or, as Deleuze saw it, from a disciplinary society, where power is exercised over bodies through discipline, supervision and training, to a much more subtle society of control. In the postmodern society of control the "mechanisms of command become [...] ever more immanent to the social field", and the normalizing apparatuses "that internally animate our common and daily practices" $\mathbf{2 2}$ exercise control that, in contrast with the disciplinary society, reaches far beyond institutions such as schools, clinics, prisons or factories. Negri and Hardt named this new form of power Empire.

In the transition from a disciplinary society to the society of control, that is situated completely in the biopolitical paradigm, the nature of resistance to power undergoes a change. In the face of this transformation Negri and

18 Michael Hardt and Antonio Negri, Multitude. War and Democracy in the Age of Empire (New York: The Penguin Press, 2004), 94.

Walter Benjamin, Illuminations, ed. Hannah Arendt (New York: Schocken Books, 2008), 257. 
Hardt, just as Deleuze had done, set for themselves a task of "finding new weapons"23, new strategies of resistance and liberation.

In the disciplinary model an individual's subjugation to the institutions of power is opposed by individual resistance. In the model of control this is no longer possible, as power no longer rules, but rather produces subjectivity. This results not only in more efficient means of controlling life, which eludes power in isolated points of resistance, as Foucault would have it, but the resistance itself is transferred into the center of the network of power. "Civil society is absorbed in the state, but the consequence of this is an explosion of the elements that were previously coordinated and mediated in civil society. Resistances are no longer marginal but active in the center of a society that opens up in networks; the individual points are singularized in a thousand plateaux".24 According to the authors of Empire Foucault misdiagnosed the dynamics and transformations of the system that he described. This particular aspect is in turn addressed by Deleuze and Guattari who "discover the productivity of social reproduction (creative production, production of values, social relations, affects, becomings), but manage to articulate it only superficially and ephemerally, as a chaotic, indeterminate horizon marked by the ungraspable event" 25 .

The task Negri and Hardt set before themselves is the description of the productive side of a biopolitical society. It has at its source the multitude, the human collective present within the network of power; "within Empire and against Empire. New figures of struggle and new subjectivities are produced in the conjuncture of events, in the universal nomadism, in the general mixture and miscegenation of individuals and populations, and in the technological metamorphoses of the imperial biopolitical machine"26. Biopolitics administers the life of the multitude and produces it, but at the same time it remains dependent upon it - the multitude can oppose biopolitics by revealing its creative, disruptive and potentially revolutionary character. In consequence of the pressures, exerted by a global market, that force migrations and globalization which in turn facilitate the mixing of cultures and races on an unparalleled scale; and of the emerging computerized networks of communication that augment the formation of previously unknown languages; the phenomena associated with the dispersed, technologized and ubiquitous model of power are combined with the productive power of the multitude.

\footnotetext{
23 Gilles Deleuze, Negotiations. 1972-1990 (New York: Columbia University Press, 1995), 178.

24 Hardt and Negri, Empire, 25.

25 Ibid., 28.

26 Ibid., 61.
} 
Deleuze demonstrated how different kinds of machines reflect the transitions that societies undergo - as they express the social forms that have created them. "Old sovereign societies worked with simple machines, levers, pulleys, clocks; but recent disciplinary societies were equipped with thermodynamic machines [... $]^{\text {27 }}$, contemporary postmodern societies have at their disposal information machines and computers. They reveal the omnipresence of power and capital, which circulates unrestrained - ignoring and nullifying borders present in the world. At the same time the biopolitical global society, just as the World Wide Web, is a democratic band of channels, highly susceptible to mutation and change, roamed by both the power and the discontent aimed against it.

The way of thinking employed by Negri and Hardt is well suited for the investigation of the character of changes contemporary societies undergo. Unfortunately they are not immune to error, particularly when they attempt to distinguish within biopolitics its negative, mechanical side: "[an] empty machine, a spectacular machine, a parasitical machine" $\mathbf{2 8}$ and the positive, creative multitude that animates it. All things considered, Negri and Hardt merely alter the hierarchy: it is not the global, imperial biopower that rules the multitude, instead it is supported by and it relies upon it. However, the authors of Multitude open a possibility of avoiding the grim outlook on biopower, that being our reality is also the worst, because almost unnoticeable, prison. The constituted network of biopolitical power is the very same one that is inhabited by resistance and creativity; it is the force defining the paths of communication and the ways of constituting subjectivity.

Choosing the notion of biopolitics as a starting point might turn out to be an inspired move if, instead of succumbing to the hopelessness accompanying the recognition of the omnipotence and inhumanity of the power that creates us, we will view it as a necessary condition for producing the revolutionary subjectivity. Both Foucault and Agamben place resistance on the margins of power. In Foucault's case the resistance is akin to an electric discharge, manifesting itself suddenly and passing just as swiftly within the dense biopolitical network of power. Agamben discovered the blind spot, independent from power, to be a by-product of the machine of power itself, that can nevertheless nullify its political agency. The real challenge is the description of the structure of global power which produces the body, and allows it to retain its productive, creative capabilities. It would shed new light upon the mechanisms of power: as the force controlling life, but also facilitating the creation of new networks

27 Deleuze, Negotiations, 180.

28 Hardt and Negri, Empire, 62. 
and configurations of bodies, new forms of corporeality and subjectivity. In this case the non-human creates the human in the form of a prisoner and an eternal rebel at the same time.

\section{Machines, Cyborgs, Hybrids}

One of postmodernism's achievements was the unmasking of the binary oppositions that gave structure to the Western philosophical tradition. Some of those dichotomies are: culture/nature, male/female, center/periphery, human/animal, civilization/barbarity, truth/falsehood, I/Other, whole/part. These pairs are not mere antonyms, but due to the first term's privileged position over the second, they constitute a hierarchy. On the basis of these binaries a form of ruling emerged that is responsible for the exclusion of the opposing elements in the hierarchy. Postmodernist thinkers discovered the oppressive nature of a structure that by praising one part of the opposition (culture, male, human, center, civilization, truth etc.), causes the repression of the other, deeming it worthless. They have recognized the dialectic act that eliminates the difference, so as to subsume it under the unifying property of the One. The postmodern project tried to oppose this logic of reducing everything to oneness, through reconstituting the overlooked counterparts of binary oppositions and the affirmation of difference. One of the effects of this endeavor was the emergence of a figure of the Other - the incomprehensible stranger, who does not belong to the familiar order of things - for whom the postmodern thinkers demanded respect and appreciation.

Negri and Hardt demonstrate that this kind of thinking is already anachronistic. The assumption that power acts through opposing binaries and dialectics, reducing the different to the identical, is simply wrong in the face of a power that is itself a hybrid, variable and decentralized. The postmodern project proved ineffective for the purpose of adequately describing the character of contemporary forms of power and for providing means of liberation from them. Dominant meta-narratives ceased to exist, so there is nothing to overpower anymore, there no longer are any enduring differentials, shattering of which could lead to liberation.

Binaries can no longer serve as a starting point, neither can attacking them for that matter. Rather, the new starting point comes from the perception of a gap, present where previously there was a line of separation. From the point of view of advanced technologies, represented in the works of the American theorist Donna Haraway, binaries have not only been subverted, but techno-digested.

Haraway points to three boundaries which were previously established and that seemed inviolable. Today we must view them as considerably 
tarnished, and draw lessons from this observation for the future. First and foremost, there is no hiatus between the human and the animal, as scientific experiments prove by exposing the familiarity between the two. I will expound on this insight in a moment. The second division lays between the space of living beings and machines. It is now under siege from technological aberrations that put to the test our certainty about the difference between the artificial and the natural, that which is born and that which is manufactured. The third line is crossed by the means of the ubiquitous miniaturization and pervasiveness of technologies. In every place and at every moment technology pervades human life and experience, to the extent where the human being is permanently and discreetly accompanied by the non-human - mixing, modifying and transforming it. The model representing the relations of the animate - inanimate, organic - mechanical, human - machine can no longer be seen in the assembly line, the alienating property of which has been ironically depicted by Charlie Chaplin in the motion picture Modern Times. Now it can be rather found in the inseparable composite of the human and the mechanical - a hybrid - in the super prosthesis of a limb or the heart-lung machine, that transposes human life beyond the corporal boundaries of the body and grants it a chance for survival in that realm.

Blending the human with the mechanical might seem a violation of taboo. The technological intervention into human life and the transformation of that which is human, by means of technology seems to pose the greatest risk. These anxieties, Heideggerian in their nature, are firmly opposed by authors who are more than happy with breaking the taboo. Bruno Latour deposes the dualities of culture and nature, subject and object, human and thing. In their place appears a "common world of humans and non-humans". The strict distinction made between the human and the non-human is a mirage, according to the French philosopher. The more we long for a separation of these two spheres, the more hybrid entities emerge that are halfway between human and machine. "Modernity - the thinker tells us - is often defined in terms of humanism, either as a way of saluting the birth of 'man' or as a way of announcing his death". In both cases what is overlooked is the "simultaneous birth of 'nonhumanity' - things, or objects, or beasts - and the equally strange beginning of a crossed-out God, relegated to the sidelines"29. To describe the human being and his/her/its existence in the world one cannot disregard humans as being-machines, their coexistence in the non-human. Latour, who obviously addresses a more widespread transformation occurring within contemporary philosophical anthropology, does not assent to the proclamations

29 Bruno Latour, We Have Never Been Modern (Massachusetts: Harvard University Press, 1993), 13. 
of the Death of Man, as "nothing is sufficiently inhuman to dissolve human beings in it and announce their death"30.

The goal is therefore the pursuit of a new place for the human in the realm of the non-human. Previous formulations of subjectivity: "the free agent, the citizen builder of the Leviathan, the distressing visage of the human person, the other of a relationship, consciousness, the cogito, the hermeneut, the inner self, the thee and thou of dialogue, presence to oneself, intersubjectivity" ${ }^{\mathbf{3 1}}$ are not able to explain man's being in the world, as they all overlook his /her/their share in things. Neither can anti-humanism, for that matter, as it dissolves the human in the network of power, language games or discourse. In their place Donna Haraway puts the figure of a cyborg, which enables her to see the figuration of modern subjectivity.

The cyborg as a product of technoculture, perceived as a hybrid, a frightful creation crossing the line of human and non-human, for Haraway became a key figure that allowed her to rethink the relation of the human to other entities in a constantly changing, technologized and mechanized world. The cyborg is a figure that ends the struggle for upholding boundaries, for subordinating nature to cultural production, the war between man and machine, at the same time it exposes the pleasure derived from the blurring of lines. In place of the opposing nature and culture there emerges a new element - the culture-nature; instead of a human being distinct from the machine we get a perverse intertwinement of the two - a cyborg.

The ambiguous character of the cyborg is among the numerous reasons Haraway chooses it to serve as a metaphor for the human condition. The creation of the cyborg is an effect of an arms race, of Western militarism and patriarchal domination, it is their illegitimate child: it represents a rebellion against culture which brought it to life, symbolizing in this respect a new configuration of culture/nature, political/personal, human/nonhuman. The paradox contained in the figure of the cyborg comes from the fact that while being a threat, a synonym of the paranoid arms race, it is at the same time a promise of a new form of the human being's functioning in a materialistic, corporal world, that allows humankind to cease fearing its kinship with the animal and the machine, as well as his partial, unfinished and incoherent identity. According to Haraway, as organic, corporal, human entities, we can enter close and intimate relationships with machines, so that they are recognized as something kindred, co-constituting human life.

30 Ibid., 137

31 Ibid., 136. 
The goal the American thinker sets before herself is not a description of a new kind of machines called cyborgs, but a diagnosis of the changes underway in contemporary society, in which "we are cyborgs", the illegitimate children of the patriarchal, militarized power. The cyborg is most of all a figure that compels us to reconsider the complexity of our time, and to become aware of the ragged borders separating the human and the mechanical, the animate and organic from the inanimate object. In the world described by Haraway as a world of webs, interlinks and communication, the cyborg is a "figure of interrelationality, receptivity, and global communication that deliberately blurs categorical distinctions (human/machine; nature/culture; male/female; oedipal/nonoedipal)"32.

Negri and Hardt point out that Haraway carries on Spinoza's project in her attempt to create a vision of the world where the human laws are not distinct from the laws of nature. Reconfigurations of the body, the transitions of sexuality, and the transformations of desire are possible in the space of freedom, where humankind is not subject to laws different to those governing animals and machines, and is not separated from them in a strict way. Thus an affirmation of mixing, flowing and change becomes possible.

The praise for the machine, mutation and hybridism marks the end of a certain phase in critical thinking that lasted from the time of Heidegger, Adorno and Horkheimer until Derrida, that "is now a closed parenthesis and leaves us faced with a new task: constructing, in the non-place, a new place; constructing ontologically new determinations of the human, of livinga powerful artificiality of being" ${ }^{\prime 3}$.

Donna Haraway's cyborg fable is a symbolic passage from the philosophical thought that perceived technology, the technological-instrumental reason as a source of impending doom, to a more nuanced concept of the computerized, technologized structure of the contemporary world. This affirmative aspect that supplements the critical and skeptical viewpoint on technology, allows a more adequate diagnosis of the changes contemporarily taking place in the world, changes that go beyond dualities and refuse to take part in the process of purification and subjugation. Finally relinquishing the besieged stronghold of the human and consenting to the fusion of the human with the non-human, culminates in the embedment of the human subject within the hybrid, human-non-human reality, where there is nothing neither pure nor static.

32 Rosi Braidotti, Nomadic Subjects. Embodiment and Sexual Difference in Contemporary Feminist Theory (New York: Columbia University Press, 1994), 105. 


\section{The Return of the Animal}

The transposition of the human into the realm of the non-human occurs as a two-phase process. At first the realization that non-human powers are at play in the production of subjectivity, to which it is subordinate, results in a crisis. But afterwards this crisis becomes a source of acknowledgment that the proper space for the human is precisely the sphere of the non-human.

The attributes of humanity such as: the soul, reason, consciousness, morality were tasked with differentiating man (sic) from all other animals. They secured his (sic) privileged position among other living beings. This position in turn granted him the right to rule over the animal world. The loss of this right opens new possibilities, as "the human, when situated as one among many, is no longer in the position of speaking for and authorizing the analysis of the animal as other, and no longer takes on the right to name, categorize, the rest of the world (...)"34.

The relation between man and animal will be analyzed in two configurations: first the relation of that which is human to that which is animal, and then the animal within the human. These two perspectives enable a reconstruction of the movement that substitutes an opposition with a creative, productive and generative relation.

The Australian philosopher Elizabeth Grosz proposes a return to Charles Darwin's theory of evolution, as it is he who discovered that the difference between the human species and the animals is quantitative, not qualitative. Darwin places humans within an evolutionary process, the nature of which is constant change from one form of life into another. The human being is placed in this drift of eternal becoming, of perpetual change and passage. He/ she/they turns out to be a temporary species, that emerged from preceding forms of humanoid animals and is heading for a transition into some new, yet unknown, species. Man is that, what is in the process of becoming an animal.

Properly human traits have their basis in the early forms of animal life from which the human being evolved: language - in the calls animals use to communicate, reason - in the preceding forms of animal rationality. It is to a large extent due to Darwin's investigations that man can now be thought of as one among many animal species. Non-human animals do not differ significantly from humans; they develop forms of community, language, taste, attractiveness, utility or rationality appropriate for their kind, just as the human being does.

According to Grosz, accepting these facts leads to the creation of a project of a "fleeting" humanity that transcends itself. This project enables a transformation of its own subject and paves the way for a procession of questions

34 Grosz, Becoming Undone, 24. 
that propel the humanities into previously uncharted territory. "How openendedly must we understand language, representation, and art (...) if we are to problematize the opposition between animal and human, and fully immerse the human in the worlds of the animal? What is distinctively human in the humanities if man is again, in the light of Darwin's rearrangement of the universe, placed in the context of animals and animal-becomings?"35, how will our perception of language change, if we take into account languages descending from that which is animal? Where are the boundaries of the humanities? What shape will the humanities assume when humans become post-human?

Rearranging the relation between the human and the animal results in deposing man (sic) from his privileged position that until now permitted him to describe and hierarchize the world, to appropriate the human and dominate the animal. Instead, situated among other animals, s/he can transcend himself or herself and proceed with his scientific endeavors in the unknown, extraordinary and fertile territories.

The second of the relations, that I have mentioned earlier, reveals the dividing line between the animal and the human within the human. A composite of body and soul, matter and spirit, vegetative power and reason - the human is a permanently divided being, through which runs the line dividing human and animal traits. What connects man to the animal world: corporeality, materiality, sensuality is separated from the distinctly human traits. Giorgio Agamben labels this logic of producing man as "humanism's anthropological machine": its primary aim is to conceal the fact that there is no such thing as a core or nature of humanity, only a chain of cuts and differences that introduce a superficial distinction between the animal and the human elements that humanity consists of. The anthropological machine produces a definition of what man really is that is mediated by that which is non-human.

The process of delineating, by means of this dynamic mechanism, distinct areas of humanitas and animalitas, creates a gap between the two - this is an area of ongoing negotiations about which life will be considered human and which, deemed as animal, will be cast away from the human community. Because the dividing line between the human and the animal is not set in stone, each society decides for itself who will be denied human traits and banished. For this reason the anthropological machine is not only capable of producing that which is human, but also disposing of what ceases to be human from the community of man.

Through the manufacturing of notions such as reason, language or consciousness that refer only to human beings and that attest to the human 
being's exceptional place among living beings, "philosophy has attributed to man a power that animals lack (and often that women, children, slaves, foreigners, and others also lack: the alignment of the most abjected others with animals is ubiquitous)"36. This introduces a disconcerting paradox into the notion "human being" - it is bestowed upon those, whose existence is deemed human and in consequence is considered dignified and worthy of protection. For this reason the problem of defining a human being and human life was always the center of attention for emancipatory, anti-racist, postcolonial and feminist movements. They all try to comprehend the relationship between domination, violence and the imposed definition of the human being, and reveal "what categories of human are classified as borderline, less than human, or already on the animal-side of the human" ${ }^{37}$. The crisis of subjectivity, the category of "man" as an instrument of rule and subjugation coincides with the point in history, when the demands of emancipatory movements, colonized nations, ethnic, racial and sexual minorities are beginning to be met. Because members of these groups have never identified with the autonomous and regal enlightenment subject, they do not strike apocalyptic or nihilistic chords in face of its proclaimed crisis or death, as some would have it. Quite the contrary - this crisis opens a possibility of finding new figurations of subjectivity that would be capable of talking in the voice of those who have been denied their own until now. This novel redefinition of the human subject courageously begins with the act of mixing it with the non-human.

In The Open Agamben introduces a metaphor for this mixing of spheres. It is a miniature from a copy of the Hebrew Bible from the collection of the Ambrosian Library in Milan. It represents the messianic banquet of the righteous on the last day - they are the God-fearing Jews who have observed the prescriptions of the Torah for their whole lives, and on the final day partake in a feast, consuming the meat of Behemoth and Leviathan, impure, mythical, biblical animals. The depicted silhouettes have human bodies, yet animal heads. This fulfilled humanity represented through animal heads, illustrates a novel relation between the human and the animal within man. This relation is no longer based on subjectifying the animal, but rather on reconciling with it. The meat feasted upon is no longer trefa, as the division between clean and unclean has ceased to exist. The same applies to the division between the human and the animal, if it were to be a reason for banishment of those considered non-human.

36 lbid., 12

37 Ibid., 15 . 
The reaction to the fear that arises when one crosses the boundary between the human and the non-human: machine or animal, is a fervent attempt to cleanse the notion "human" of all traces of the non-human. The strategy of isolation and purification ultimately fails. The categories charged with safeguarding the preordained structure and preventing humans from becoming non-human, stopped being impermeable.

Another reaction to the confusion, to this ritual impurity, might be laughter. The very same that led Foucault to write The Order of Things:

This book first arose out of a passage in Borges, out of the laughter that shattered, as I read the passage, all the familiar landmarks of my thought - our thought, the thought that bears the stamp of our age and our geography - breaking up all the ordered surfaces and all the planes with which we are accustomed to tame the wild profusion of existing things, and continuing long afterwards to disturb and threaten with collapse our age-old distinction between the Same and the Other. This passage quotes a 'certain Chinese encyclopedia' in which it is written that 'animals are divided into: (a) belonging to the Emperor, (b) embalmed, (c) tame, (d) sucking pigs, (e) sirens, (f) fabulous, (g) stray dogs, (h) included in the present classification, (i) frenzied, (j) innumerable, (k) drawn with a very fine camelhair brush, (l) et cetera, $(\mathrm{m})$ having just broken the water pitcher, (n) that from a long way off look like flies' ${ }^{\mathbf{3 8}}$.

The laughter that does not fear a confusion of categories can give rise to a new way of thinking that surpasses predefined borders. A way of thinking, which in a cyborg, monkey or machine discovers a kinship with humanity and draws conclusions from that. The human fear of losing his/hers/their humanity gives way to hope for the human being's salvation in spite of their proclaimed "death".

Translation: Rafat Pawluk

38 Michel Foucault, The Order of Things. An archeology of the human sciences (London: Routledge, 2002), XVI. 